\title{
A Model for Compartment Fire Behavior Incorporating Fire Growth and Vitiation
}

\author{
DAISUKE GOTO ${ }^{1}$, YOSHIFUMI OHMIYA ${ }^{1}$, and MICHAEL A. DELICHATSIOS ${ }^{2}$ \\ ${ }^{1}$ Department of Science and Technology \\ Tokyo University of Science \\ 2641 Yamazaki, Noda, Chiba 278-8510, Japan \\ ${ }^{2}$ FireSERT \\ University of Ulster \\ Shore Road, Newtownabbey, Co. Antrim, BT37 0QB, UK
}

\begin{abstract}
The burning behavior for non-charring fuels is modeled to predict the fire behavior in a compartment. This modeling considers the following phenomena: (i) the reduction of heat transfer from flames due to lack of oxygen mass fraction; and (ii) the thermal feedback from the smoke layer and walls. In addition, a compartment integrated zone model is developed to obtain the parameters which are necessary for the prediction of fuel burning behavior. Namely, this approach applies a two-zone model for the growth or preflashover stage and a one-zone model for the fully-developed or post-flashover stage which also incorporates the fuel burning behavior. Fire experiments in a cubic compartment are conducted to validate this model. Overall, calculations of this integrated compartment model give good agreement with the experiments of mass loss rate and temperature in the compartment.
\end{abstract}

KEYWORDS: compartment fires, fire behavior, heat transfer, stoichiometric ratio, zone models.

\section{NOMENCLATURE LISTING}
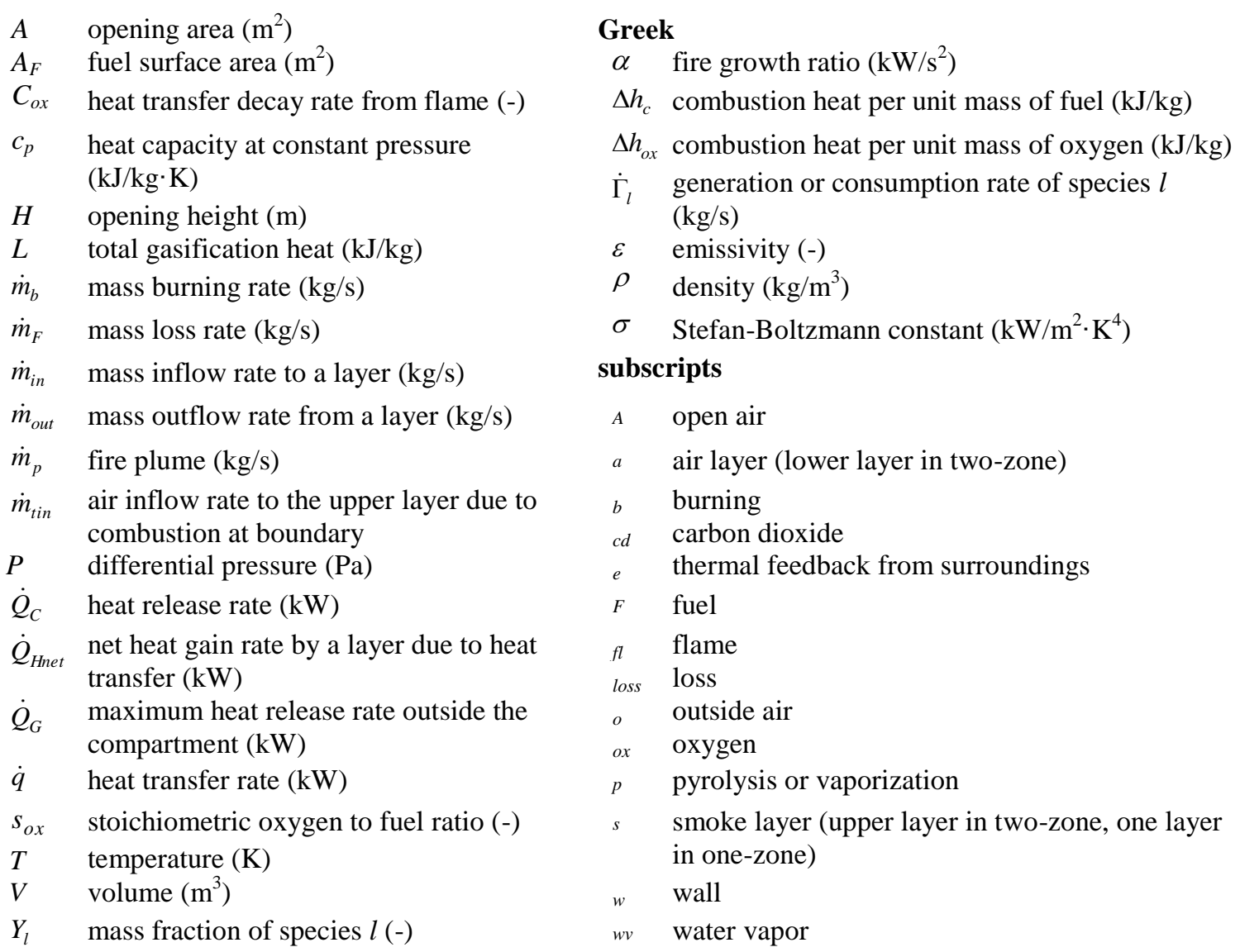


\section{INTRODUCTION}

For the prediction of fire spread in a building, knowledge of the amount of smoke and flammable gases flowing out of the compartment is essential. The ejected combustion products depend on the fuel burning behavior (mass loss rate) as the ventilation varies during the fire growth in the compartment. The combustion in the compartment will be fuel-controlled if there is a sufficient amount of oxygen, or will be ventilation-controlled if not. Meanwhile, to predict fire behavior in a building, researchers have actively developed numerical analysis models based on the zone concept [1]. Though the physical properties in zone are not strictly uniform [1], zone models provide valuable information for fire safety design if the target phenomena are limited. In addition, zone models require much less time for computations than a CFD model. Currently, the fuel burning behavior in zone models is determined at steady-state conditions by the opening parameters (e.g. for the mass loss rate [2], and for the heat release rate), or fire safety designers determine the behavior according to fuel parameters within a compartment by assuming a fire growth rate (e.g. Ref. [3]). Consequently, the former approach limits the prediction of fire phase to a steady fully-developed fire, whereas the latter approach may cause inaccurate evaluation about fire phenomena because of the difficulty of describing the fuel burning behavior based on the conditions of openings and/or fuels.

The fuel mass loss rate and fire growth depend on the heat transfer from the flame and on the thermal feedback from surroundings whereas the heat transfer from the flame depends on the ambient oxygen mass fraction [4]. To predict the fuel burning behavior based mainly on the mass loss rate, this paper combines two models; (i) one for the fuel burning behavior based on oxygen supply and the rate of heat transfer; and (ii) the other for an integrated compartment model, composed of a two-zone model followed by a one-zone model. After the fuel burning model is incorporated into the compartment zone model, its validity is verified by the experiments performed in a small-scale compartment.

The consideration of the fuel burning behavior makes it possible to be realistic for practical applications regarding the mass and heat release rate histories as well as smoke production rates through openings for varying ventilation conditions in the compartment. Although, CFD models could be applied, our experience with it has shown that they are not capable and credible to predict the varying fire conditions in a compartment fire which range from non-premixed to premixed conditions and poorly model techniques of soot and radiation.

\section{FORMULATION OF FUEL BURNING BEHAVIOR}

The burning behavior of a fuel in a compartment is related to the following parameters: (i) the mass loss rate of a fuel; (ii) the heat transfer from flames; (iii) the thermal feedback from surroundings; (iv) the heat release rate inside a compartment; (v) the consumption and production rates of chemical species; and (vi) the heat release rate outside a compartment.

\section{Mass Loss Rate}

The mass loss rate at quasi-steady and thermally thick conditions is determined by the heat transferred and lost from the surface and the thermal decomposition energy as expressed by:

$\dot{m}_{F} L=\dot{q}_{f l}+\dot{q}_{e}-\dot{q}_{\text {loss }}$.

where $\dot{q}_{f l}$ is the radiative and convective heat transfers from the flames, $\dot{q}_{e}$ is the thermal feedback from surroundings, $\dot{q}_{\text {loss }}$ is the heat loss from fuel surface and $L$ is the total heat of gasification $\left(=\Delta h_{v}+c_{p, p}\left(T_{p}-T_{o}\right)\right)$. In the open, the mass loss rate and the heat loss rate from the fuel can be expressed as $\dot{m}_{F}=\dot{m}_{F A}^{\prime \prime} A_{F}$ and $\varepsilon_{F} \sigma\left(T_{p}^{4}-T_{o}^{4}\right) A_{F}$ respectively. It follows that the heat transfer rate from the flame in the open can be obtained as follows from Eq. 1.

$\dot{q}_{f l A}=A_{F}\left\{\dot{m}_{F A}^{\prime \prime} L+\varepsilon_{F} \sigma\left(T_{p}^{4}-T_{o}^{4}\right)\right\}$ 
where $A_{F}$ is the fuel surface area, $\dot{m}_{F A}^{\prime \prime}$ is the mass loss flux in the open, $T_{o}$ is the outside air temperature and initial temperature of the fuel, $T_{p}$ is the pyrolysis or vaporization temperature and $\varepsilon_{F}$ is the fuel surface emissivity.

The heat flux from the flame decreases with the ambient oxygen mass fraction [4] existing in a compartment at under-ventilated conditions. This reduction of the flame heat transfer depends on the equivalence ratio of the gasified fuel and oxygen in the compartment. Following Eq. 3, it is assumed that the flame heat transfer decreases as much as the ratio of the amount of available oxygen to the required amount of oxygen for the burning of the gasification fuel. The reduction rate can be expressed as follow.

$$
C_{o x}=\min \left[\frac{\dot{m}_{o x, \infty}}{s_{o x} \dot{m}_{F, \infty}}, 1\right]
$$

where $\dot{m}_{o x, \infty}$ and $\dot{m}_{F, \infty}$ are the amounts of oxygen available in the compartment for combustion and gasified fuel respectively and $s_{o x}$ is the stoichiometric oxygen-to-fuel ratio. Consequently, the heat transfer rate from flame inside a compartment is given by:

$\dot{q}_{f l}=C_{o x} A_{F}\left\{\dot{m}_{F A}^{\prime \prime} L+\varepsilon_{F} \sigma\left(T_{p}^{4}-T_{o}^{4}\right)\right\}$.

As shown in Fig. 1, the flaming fuel area denoted as $A_{F b}$ decreases when the amount of oxygen in the vicinity of the fire source becomes insufficient $[5,6]$. This phenomenon is related to the reduction of heat transfer from the flames. Hence it is assumed that the heat transfer rate from the flames decreases as much as the reduction of the flaming fuel area. In addition, thermal decomposition occurs at the non-flaming fuel area denoted as $A_{F p}$. These areas can be expressed respectively as:

$A_{F b}=C_{o x} A_{F}$

$A_{F p}=\left(1-C_{o x}\right) A_{F}$.

Here the radiative heat transfer from the flames to the non-flaming fuel area is ignored. In addition, the flame height should be low enough to be defined by the flaming fuel area. The heat loss from the fuel is:

$\dot{q}_{\text {loss }}=\varepsilon_{F} \sigma\left(T_{p}^{4}-T_{o}^{4}\right)\left(A_{F b}+A_{F p}\right)$.

Therefore, by substituting Eqs. 5 and 7 into Eq. 1 and using Eq. 6, the mass loss rate is given by:

$\dot{m}_{F}=\dot{m}_{F A}^{\prime \prime} A_{F b}+\frac{\dot{q}_{e}-\varepsilon_{F} \sigma\left(T_{p}^{4}-T_{o}^{4}\right) A_{F p}}{L}$.

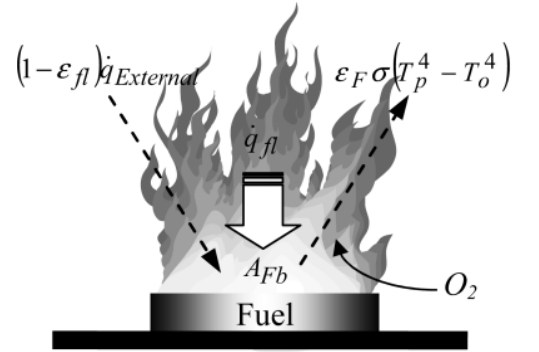

(a)

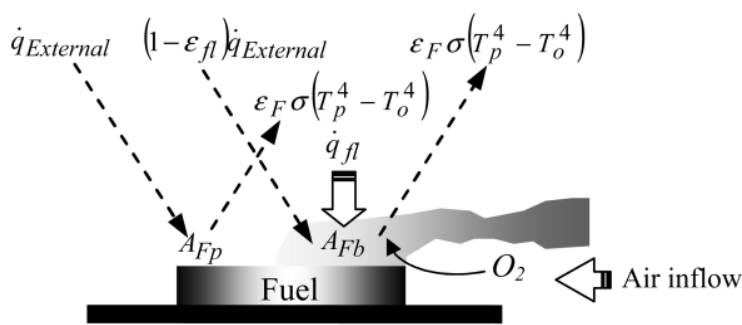

(b)

Fig. 1. Schematic of burning model and its balance of heat transfer at fuel: (a) fuel-lean; (b) fuel-rich. 


\section{Amounts of Available Oxygen and Gasified Fuel for Combustion}

These amounts are expressed in terms of quantities specified in the zone model owing to the flow and combustion in the compartment. The amounts of available oxygen and pyrolysed fuel in Eq. 3 consider the three different patterns shown in Fig. 2 as explained next.

Figure 2a shows the case in a fuel-controlled fire. In this case, the flame heat transfer to the fuel is determined by gasification of the fuel and air entrainment. The amounts of available oxygen and gaseous fuel can be expressed as:

$\left\{\begin{array}{l}\dot{m}_{o x, \infty}=\left(\min \left[\dot{m}_{p}, \dot{m}_{p f}\right]-\dot{m}_{F}\right) Y_{o x, o}+\max \left[\dot{m}_{p f}-m_{p}, 0\right] Y_{o x, s} \\ \dot{m}_{F, \infty}=\dot{m}_{F}+\max \left[\dot{m}_{p f}-\dot{m}_{p}, 0\right] Y_{F, s}\end{array}\right.$

where $\dot{m}_{p}$ and $\dot{m}_{p f}$ are the entrainment rates of the fire plume below the interface layer and the intermittent flame height respectively, whereas $Y_{l}$ is the mass fraction of species $l$.

Figure $2 \mathrm{~b}$ demonstrates the case that fuel is burning at the boundary of upper and lower layers. This case was observed in experiments when smoke layer came down very low with respect to ceiling height. In this case, the combustion mainly depends on the amounts of oxygen and gasification fuels in the upper layer because its layer descends close to fire source and floor surface, and the amount of entrainment becomes very limited. The extent of the region that the heat transfer affects fuel, the dotted frame as illustrated in Fig. $2 b$, is not well defined. However, the ratio of the oxygen and pyrolysed fuel is constant in any region because the mass fraction of chemical species within a layer is uniform on the zone concept. Therefore the amounts of available oxygen and gasification fuels can be expressed as follows by using the net amounts of the oxygen and gasification fuel in the upper layer.

$$
\left\{\begin{array}{l}
\dot{m}_{o x, \infty}=\rho_{s} V_{s} Y_{o x, s}+\dot{m}_{i n, s} Y_{o x, o}-\dot{m}_{o u t, s} Y_{o x, s} \\
\dot{m}_{F, \infty}=\rho_{s} V_{s} Y_{F, s}+\dot{m}_{F}-\dot{m}_{o u t, s} Y_{F, s}
\end{array}\right.
$$

Where $\dot{m}_{i n, s}$ is the mass inflow rate to the upper layer in two-zone or to the layer in one-zone, $\dot{m}_{\text {out }, s}$ is the mass outflow rate from these layers, $\dot{m}_{\text {tin }}$ is the flow rate from lower layer to upper layer due to combustion at boundary. As for $\dot{m}_{\text {tin }}$, we assume that the lack of the upper layer oxygen to the oxygen consumption rate, $\Gamma_{o x}$, based on the mass burning rate, causes the combustion with the lower layer oxygen at boundary, and the buoyancy force due to the combustion yields inflow from lower to upper layer. The flow rate can be given by

$\dot{m}_{t i n}=\frac{\max \left[\left(-\dot{\Gamma}_{o x}\right)-\left\{\rho_{s} V_{s} Y_{o x, s}+\left(\dot{m}_{p}-\dot{m}_{F}\right) Y_{o x, o}-\dot{m}_{o u t, s} Y_{o x, s}\right\}, 0\right]}{Y_{o x, a}}$.

Figure 2c shows the case in one layer zone. The amounts of available oxygen and gasification fuel in one layer can be expressed as Eq. 10 in a similar to the case of Fig. 2b.

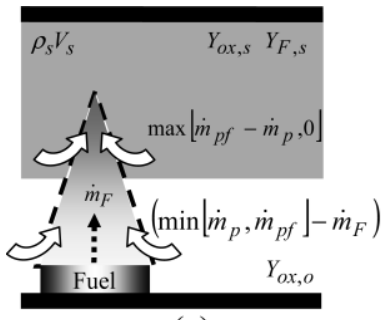

(a)

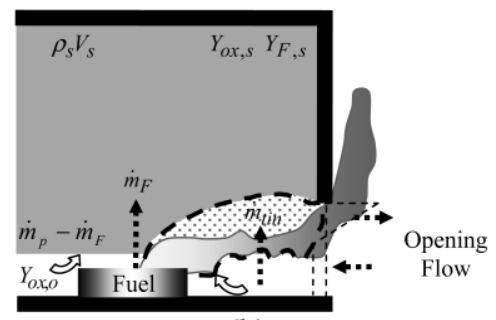

(b)

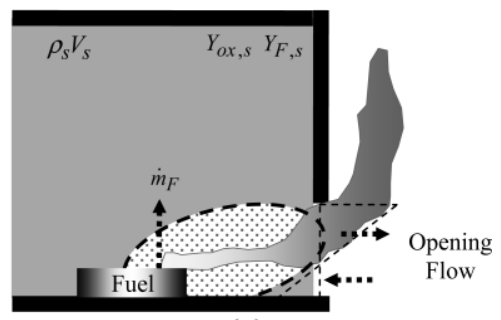

(c)

Fig. 2. Factors in influencing the fuel / air equivalence ratio in the compartment: (a) two-layer zone ( $\left.\dot{m}_{\text {tin }}=0\right)$; (b) two-layer zone $\left(\dot{m}_{\text {tin }}>0\right)$; (c) one-layer zone. 


\section{Rate of Thermal Feedback from Surroundings}

The fuel in a compartment also receives heat from the surroundings in addition to heat from the flame. This thermal feedback promotes the mass loss rate compared with that in the open air. The thermal feedback is primarily radiative heat transfer from layers and walls:

$\dot{q}_{e}=\varepsilon_{F} \sigma\left\{F_{s} \varepsilon_{s}\left(T_{s}^{4}-T_{o}^{4}\right)+F_{w}\left(1-\varepsilon_{s}\right) \varepsilon_{w}\left(T_{w}^{4}-T_{o}^{4}\right)\right\} \times\left\{\left(1-\varepsilon_{f l}\right) A_{F b}+A_{F p}\right\}$.

where $F_{s}$ is the geometric factor from the top of fuel to the smoke layer, $F_{w}$ is the geometric factor from the top of fuel to the walls which are in contact with smoke layer, $T_{w}$ is the temperature of the walls which are in contact with smoke layer, $\varepsilon_{s}$ is the gas emissivity, $\varepsilon_{w}$ is the wall emissivity and $\varepsilon_{f l}$ is the flame emissivity.

\section{Heat Release Rate}

The heat release rate, which is determined by the reaction of gasification fuel and oxygen, governs the quantity of burning and the extent of increasing compartment temperature inside a compartment. In this model, the following equations are formulated to describe fuel-controlled and ventilation-controlled fires.

In the fuel-controlled fire, all of gasification fuel inside a compartment combust because the sufficient amount of oxygen exists. Hence this heat release rate is calculated by multiplying the net amount of gasification fuel in the layer by the combustion heat of fuel, $\Delta h_{c}$. The heat release rate for the decay period, $\dot{Q}_{C D}$, is also calculated in a similar way.

$\dot{Q}_{C F}=\left(\rho_{s} V_{s} Y_{F, s}+\dot{m}_{F}-\dot{m}_{\text {out }, s} Y_{F, s}\right) \Delta h_{c}$

In the ventilation-controlled fire, the heat release rate can be expressed by the following equation because the combustion is limited by the net amount of oxygen in the layer. Here when combustion occurs at the boundary of the layer (i.e. $\dot{m}_{t i n}>0$ ), it is assumed that the oxygen in the lower layer is also consumed and burned.

$\dot{Q}_{C V}=\left(\rho_{s} V_{s} Y_{o x, s}+\dot{m}_{i n, s} Y_{o x, o}-\dot{m}_{o u t, s} Y_{o x, s}\right) \frac{\Delta h_{c}}{s_{o x}}$

Figure 3 illustrates the transition of the heat release rate. The calculation of the heat release rate will start with the fuel-controlled, $\dot{Q}_{C F}$, and then switch to that of the decay period, $\dot{Q}_{C D}$, when the relation between the quantity of total heat release of fuel, $\dot{Q}_{\text {all }}$, and the total consumption heat comes under the condition of Eq. 15 (point A). Subsequently, the heat release rate will switch that for the ventilation-controlled, $\dot{Q}_{C V}$, if $\dot{Q}_{C F}>\dot{Q}_{C V}$ (point B). Afterwards, $\dot{Q}_{C F}$ diminishes if the condition corresponds to Eq. 15 (point C), and then the heat release rate will switch to that of the decay period if $\dot{Q}_{C F}<\dot{Q}_{C V}$ (point D).

$\sum_{t=t_{d}}^{t_{\text {end }}} \alpha_{d}\left(t_{\text {end }}-t\right)^{2}>Q_{\text {all }}-\sum_{t=0}^{t} \dot{Q}_{C F}$

Here, on the calculation of the heat release rate, the flaming and non-flaming fuel areas in Eqs. 5 and 6 are also conveniently derived from $\alpha t^{2}$ fire until the flame spreads the entire surface area of fuel besides $C_{o x}$. In a fire decay period, it is conveniently calculated by $\alpha_{d}\left(t_{e}-t\right)^{2}$ fire. 


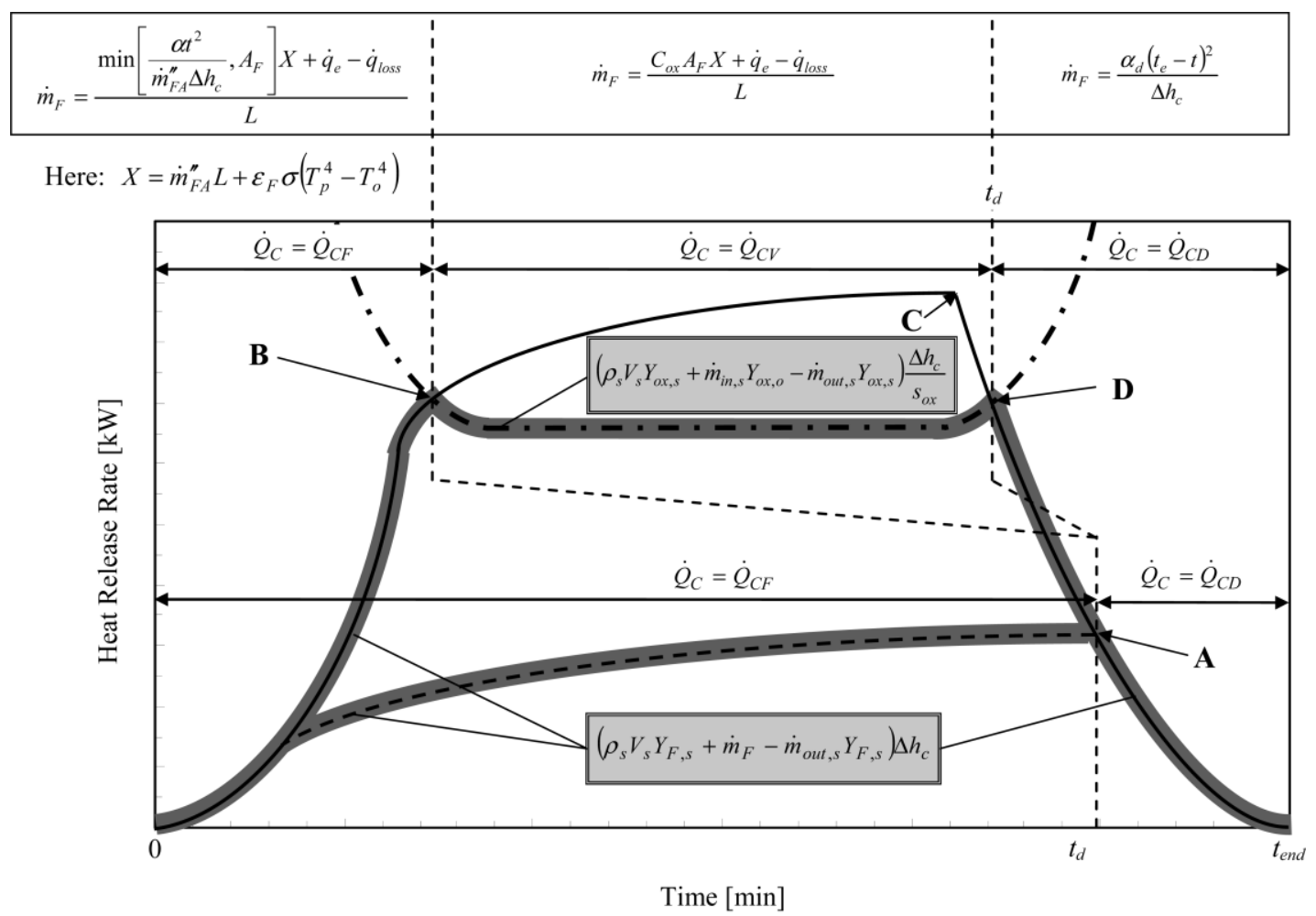

Fig. 3. Transition of heat release rate.

\section{Consumption and Generation Rates of Chemical Species}

The consumption or generation rates of chemical species $l, \dot{\Gamma}_{l}$, and unburned gasification fuel are presented as common properties of all fuel types. The rates for other chemical species are calculated according to fuels. The oxygen consumption rate can be expressed as following equation based on the stoichiometric ratio.

$\dot{\Gamma}_{o x}=-s_{o x} \dot{m}_{b}$

where $\dot{m}_{b}=\left\{\begin{array}{ll}\dot{Q}_{C F} / \Delta h_{c} & \left(\dot{Q}_{C F} \leq \dot{Q}_{C V}\right) \\ \dot{Q}_{C V} / \Delta h_{c} & \left(\dot{Q}_{C F}>\dot{Q}_{C V}\right)\end{array}\right.$.

It is assumed that unburned gas is yielded inside a compartment when $\dot{m}_{F} \Delta h_{c}$ exceeds the heat release rate of the ventilation-controlled fire. Hence the generation rate of the unburned gas can be expressed as

$\dot{\Gamma}_{F}=\max \left[\frac{\dot{m}_{F} \Delta h_{c}-\dot{Q}_{C V}}{\Delta h_{c}}, 0\right]$.

\section{Heat Release Rate of Unburned Gas outside a Compartment}

The unburned gas inside a compartment is ejected through an opening due to the ventilation effect induced by the pressure difference between inside and outside a compartment. Subsequently, the ejected gasification fuel reacts with oxygen outside the compartment. Hence the maximum heat release rate of ejected flame is given by

$\dot{Q}_{G}=Y_{F, s} \dot{m}_{\text {out }, s} \Delta h_{c}$. 


\section{FORMULATION OF INTEGRATED ZONE MODEL}

The variations of temperature and chemical species mass fractions according to the fire phase are necessary for the prediction of the fuel burning behavior. Then two models are integrated to predict these parameters. Figure 4 illustrates the schematic of this model. The model includes a two-zone model for a growth fire and a one-zone model for a fully-developed fire. The two-zone model is divided into two zones, an upper smoke layer and a lower air layer, and assumed that the physical quantity within each zone is uniform. The one-zone model is assumed that the gas inside the compartment is sufficiently mixed and the physical quantity of the zone is uniform. The calculation begins with the two-zone model, and then is switched to the one-zone model when the fire becomes fully-developed.

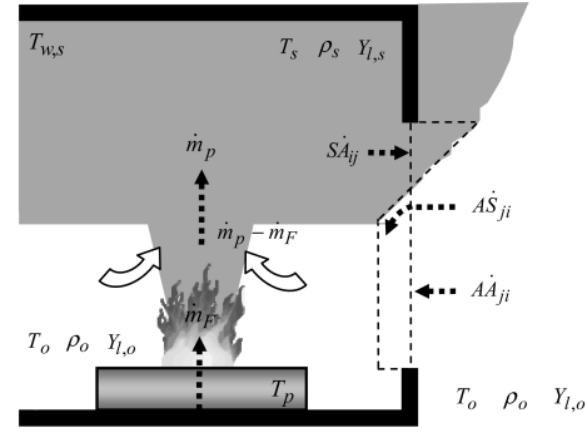

(a)

Upper Layer Mass + Lower Layer Mass

Upper Layer Energy + Lower Layer Energy

Upper Layer Species Mass + Lower Layer Species Mass
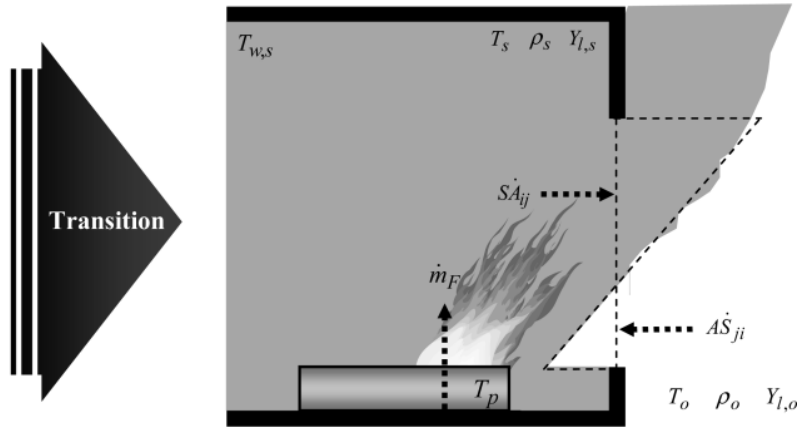

(b)

$=\quad$ One Layer Mass

$=\quad$ One Layer Energy

$=\quad$ One Layer Species Mass

Fig. 4. Schematic of integrated zone model: (a) two-zone model; (b) one-zone model.

\section{Conservation of Zone and State of Gas}

The conservation equations of zone and the state equation of gas are listed in Table 1. The conservation equations for the one-zone model are obtained by adding the corresponding equations for the upper and lower layers. Here $\dot{Q}_{\text {Hnet }}$ is the net heat gain rate by a smoke layer due to heat transfers from wall, fuel and outdoor, $A \dot{A}$ is the flow rate from an air layer to an air layer, $A \dot{S}$ is the flow rate from an air layer to an air layer through a smoke layer, $\dot{S A}$ is the flow rate from a smoke layer to an air layer. These opening flow rates are given by using equations in the model proposed by Tanaka [7].

Table 1. Conservation of zone and state of gas.

\begin{tabular}{|c|c|c|}
\hline \multirow{2}{*}{$\begin{array}{l}\text { Conservation of } \\
\text { mass }\end{array}$} & Upper-layer & $\frac{d}{d t}\left(\rho_{s} V_{s}\right)=\dot{m}_{p}+\dot{m}_{t i n}-\sum_{j=1}^{n}\left(s \dot{A}_{i j}\right)$ \\
\hline & Lower-layer & $\frac{d}{d t}\left(\rho_{o} V_{a}\right)=-\left(\dot{m}_{p}^{\prime}-\dot{m}_{F}\right)-\dot{m}_{t i n}+\sum_{j=1}^{n}\left(A S_{j i}+A \dot{A}_{j i}-A \dot{A}_{i j}\right)$ \\
\hline \multirow{2}{*}{$\begin{array}{c}\text { Conservation of } \\
\text { energy }\end{array}$} & Upper-layer & $\frac{d}{d t}\left(c_{p} \rho_{s} V_{s} T_{s}\right)=\dot{Q}_{C}+\dot{Q}_{\text {Hnet,s}}+c_{p} \dot{m}_{F} T_{p}+c_{p}\left\{\left(\dot{m}_{p}-\dot{m}_{F}\right)+\dot{m}_{\text {tin }}\right\} T_{o}-c_{p} \sum_{j=1}^{n}\left(s \dot{A}_{i j} T_{s}\right)$ \\
\hline & Lower-layer & $\frac{d}{d t}\left(c_{p} \rho_{o} V_{a} T_{o}\right)=-c_{p}\left\{\left(\dot{m}_{p}-\dot{m}_{F}\right)+\dot{m}_{t i n}\right\} T_{o}+c_{p} \sum_{j=1}^{n}\left(A \dot{S}_{j i} T_{o}^{j}+A \dot{A}_{j i} T_{o}^{j}-A \dot{A}_{i j} T_{o}\right)$ \\
\hline \multirow{2}{*}{$\begin{array}{l}\text { Conservation of } \\
\text { chemical species }\end{array}$} & Upper-layer & $\frac{d}{d t}\left(\rho_{s} Y_{l, s} V_{s}\right)=\dot{\Gamma}_{l}+\left\{\left(\dot{m}_{p}-\dot{m}_{F}\right)+\dot{m}_{t i n}\right\} Y_{l, o}-\sum_{j=1}^{n}\left(s \dot{A}_{i j} Y_{l, s}\right)$ \\
\hline & Lower-layer & $\frac{d}{d t}\left(\rho_{o} Y_{l, o} V_{a}\right)=-\left\{\left(\dot{m}_{p}-\dot{m}_{F}\right)+\dot{m}_{t i n}\right\} Y_{l, o}+\sum_{j=1}^{n}\left(A \dot{S}_{j i} Y_{l, o}^{j}+A \dot{A}_{j i} Y_{l, o}^{j}-A \dot{A}_{i j} Y_{l, o}\right)$ \\
\hline Gas state & \multicolumn{2}{|c|}{$\rho T=\frac{P M}{R}=$ const. $(\approx 353)$} \\
\hline
\end{tabular}




\section{Transition of Zone Model}

\section{Transition Conditions}

A fully-developed fire is the stage that enclosure volume is stirred and intensive combustion continues steadily. The rapid expansion of combustion due to flashover usually causes this stage, and a factor of the outbreak is strong heat flux at floor level. However, the ignition of unburned gas due to the heat flux could not always cause sufficient churning inside the compartment and the maintenance of a one-zone formation, but only the expansion of combustion. Consequently, the maintenance of the formation as shown in Fig. $4 \mathrm{~b}$ is probably made by the ventilation-controlled fire that incoming oxygen through opening combusts instantaneously. Therefore it assumes that the satisfaction of following two conditions causes the transition from the two-zone model to the one-zone model.

\section{High Heat Flux at Floor Level}

As the radiative heat flux at the center of the floor level, $\dot{q}_{\text {floor }}^{\prime \prime}$, calculated by Eq. 20 reaches $20 \mathrm{~kW} / \mathrm{m}^{2}$ [8], flashover could occur.

$$
\dot{q}_{\text {floor }}^{\prime \prime}=\varepsilon_{s} \sigma T_{s}^{4} F_{\text {floor }, s}+\left(1-\varepsilon_{s}\right) \varepsilon_{w} \sigma T_{w}^{4} F_{\text {floor }, w}
$$

where $F_{\text {floor,s }}$ is the geometric factor from the center of the floor to the smoke layer, $F_{\text {floor,w }}$ is the geometric factor from the center of the floor to the walls which are in contact with the smoke layer.

\section{Generation of Large Amount of Unburned Gas}

The expansion of combustion requires unburned gas to be ignited, and the continuous generation of the gas probably causes churning inside the compartment. That is, the consumption of almost all of the oxygen inside the compartment (i.e. the required amount of oxygen for the combustion of gasification fuel exceeds the net amount of oxygen in the compartment) causes intensive combustion, which probably leads to transition to one-zone. It follows that this condition is given by

$$
s_{o x}\left(\rho_{s} V_{s} Y_{F, s}+\dot{m}_{F}-S \dot{A}_{i j} Y_{F, s}\right)>\left\{\rho_{o} V_{a} Y_{o x, o}+\left(A \dot{S}_{j i}+A \dot{A}_{j i}-A \dot{A}_{i j}\right) Y_{o x, o}\right\}+\left(\rho_{s} V_{s} Y_{o x, s}-S \dot{A}_{i j}\right) \text {. }
$$

\section{Transition of Predicted Values}

The conservation equations for transition from two-zone (2Z) to one-zone (1Z) can be expressed as below.

Conservation of energy: $c_{p} \rho_{s(1 Z)} V_{s(1 Z)} T_{s(1 Z)}=c_{p} \rho_{s(2 Z)} V_{s(2 Z)} T_{s(2 Z)}+c_{p} \rho_{a} V_{a} T_{a}$

Conservation of chemical species: $\rho_{s(1 Z)} V_{s(1 Z)} Y_{l, s(1 Z)}=\rho_{s(2 Z)} V_{s(2 Z)} Y_{l, s(2 Z)}+\rho_{a} V_{a} Y_{l, a}$

Conservation of mass: $\rho_{s(1 Z)} V_{s(1 Z)}=\rho_{s(2 Z)} V_{s(2 Z)}+\rho_{a} V_{a}$

Furthermore, the conservation of energy at an arbitrary point inside a wall can be expressed as follows.

$$
\rho_{w} A_{T} \Delta x_{i} T_{w s(1 Z), i}=\rho_{w} A_{w a} \Delta x_{i} T_{o, i}+\rho_{w} A_{w s(2 Z)} \Delta x_{i} T_{w s(2 Z), i}
$$

where $A_{T}$ is the total surface area inside a compartment, $\Delta x_{i}$ is the segmented distance to wall in the direction of depth and $\rho_{w}$ is the density of wall.

The predictions of compartment temperature, mass fraction of chemical species and wall temperature are transferred by the following equations at the transition of model. Here the compartment temperature is given by using that $c_{p}$ is expressed by a liner function of temperature [9], Eq. 22 and gas state in Table 1. 
The mass fraction of chemical species $l$ is derived from Eq. 23, Eq. 24 and the gas state. Wall temperature is derived from Eq. 25.

$$
\left\{\begin{array}{l}
T_{s(1 Z)}=\frac{V_{s(2 Z)} T_{s(2 Z)}+V_{a} T_{a}}{V_{s(2 Z)}+V_{a}} \\
Y_{l, s(1 Z)}=\frac{T_{s(2 Z) V_{a} Y_{l, a}+T_{a} V_{s(2 Z)} Y_{l, s(2 Z)}}}{T_{s(2 Z)} V_{a}+T_{a} V_{s(2 Z)}} \\
T_{w s(1 Z), x}=\frac{A_{w s(2 Z) T_{w s}(2 Z), x}+A_{w a} T_{o}}{A_{T}}
\end{array}\right.
$$

\section{VERIFICATION OF THE MODEL}

A computer program model, which was incorporated the formulation of the fuel burning behavior into the integrated zone model, was developed. The validity of this model was verified by the experiments with a scaled model of a compartment.

\section{Experiment Overview}

A cubic scaled compartment with an opening was used in the experiments. This compartment was comprised of $0.1 \mathrm{~m}$ thick ceramic boards and its inner size was measured $1.0 \mathrm{~m} \times 1.0 \mathrm{~m} \times 1.0 \mathrm{~m}$. The opening conditions were set six patterns according to the floor area of the compartment. Methanol was used as the fuel. The details of the experimental conditions are listed in Table 2.

The fuel mass loss rate is an important parameter governing compartment fire behavior. The temperature inside compartments is also similar parameter in predicting the possible damage caused by fire, and is closely linked with the mass loss rate. That is why these two parameters were measured. The mass loss rate was measured for a period of one second with three beam-type load cells. The temperature inside the compartment was measured every one second by Type-K thermocouples (radius $0.65 \mathrm{~mm}$ ) that were placed on the opposite angle in the corner of walls.

Table 2. Experimental conditions.

\begin{tabular}{|c|c|c|c|c|c|c|c|}
\hline Opening & Unit & \multicolumn{6}{|c|}{ Values } \\
\hline$A$ / Floor area & - & $1 / 50$ & $2 / 50$ & $5 / 50$ & $10 / 50$ & $15 / 50$ & $20 / 50$ \\
\hline$W$ & $\mathrm{~m}$ & 0.1 & 0.14 & 0.225 & 0.32 & 0.39 & 0.45 \\
\hline $\boldsymbol{H}$ & $\mathrm{m}$ & 0.2 & 0.28 & 0.45 & 0.64 & 0.78 & 0.9 \\
\hline$A H^{1 / 2}$ & $\mathrm{~m}^{5 / 2}$ & 0.0089 & 0.0207 & 0.068 & 0.1638 & 0.2686 & 0.3842 \\
\hline Fuel & Unit & \multicolumn{6}{|c|}{ Values } \\
\hline Type & - & \multicolumn{2}{|c|}{$\mathrm{A} 1$} & \multicolumn{2}{|c|}{$\mathrm{A} 2$} & \multicolumn{2}{|c|}{ A4 } \\
\hline Size & $\mathrm{m} \times \mathrm{m}$ & \multirow{2}{*}{\multicolumn{2}{|c|}{$\begin{array}{c}0.32 \times 0.32 \\
0.1\end{array}$}} & \multirow{2}{*}{\multicolumn{2}{|c|}{$\begin{array}{c}0.45 \times 0.45 \\
0.2\end{array}$}} & \multirow{2}{*}{\multicolumn{2}{|c|}{$\begin{array}{c}0.64 \times 0.64 \\
0.41\end{array}$}} \\
\hline$A_{F}$ & $\mathrm{~m}^{2}$ & & & & & & \\
\hline Weight & $\mathrm{kg}$ & \multicolumn{6}{|c|}{2.38} \\
\hline
\end{tabular}

\section{Calculation Conditions}

The calculation conditions are presented in Table 3. 
Table 3. Calculation conditions $[10,11]$.

\begin{tabular}{|c|c|c|c|c|c|c|c|c|}
\hline$<$ Wall $>$ & \multicolumn{8}{|c|}{ Ceramic board } \\
\hline parameter & & $c_{p}(\mathrm{~kJ} / \mathrm{kg} / \mathrm{K})$ & \multicolumn{3}{|c|}{$\rho_{w}\left(\mathrm{~kg} / \mathrm{m}^{3}\right)$} & \multicolumn{3}{|c|}{$\varepsilon_{w}(-)$} \\
\hline Value & & 1.0467 & \multicolumn{3}{|c|}{250} & \multicolumn{3}{|c|}{1.0} \\
\hline$<$ Fuel > & \multicolumn{8}{|c|}{ Methanol } \\
\hline Parameter & $\begin{array}{c}L \\
(\mathrm{~kJ} / \mathrm{kg}) \\
\end{array}$ & $\dot{m}_{F A}^{\prime \prime}\left(\mathrm{kg} / \mathrm{s} / \mathrm{m}^{2}\right)$ & $s_{o x}(-)$ & $T_{p}(\mathrm{~K})$ & $\begin{array}{l}\alpha\left(=\alpha_{d}\right) \\
\left(\mathrm{kW} / \mathrm{s}^{2}\right)\end{array}$ & $\begin{array}{c}\Delta h_{c} \\
(\mathrm{~kJ} / \mathrm{kg})\end{array}$ & $\begin{array}{c}\Delta h_{o x} \\
(\mathrm{~kJ} / \mathrm{kg})\end{array}$ & $\varepsilon_{F}(-)$ \\
\hline Value & 1195 & $\begin{array}{c}0.015(\mathrm{D}<0.6) \\
0.022(0.6<\mathrm{D}<3.0)\end{array}$ & $\frac{\Delta h_{c}}{\Delta h_{o x}}$ & 338 & $\begin{array}{l}\text { Ultra fast } \\
(0.19)\end{array}$ & 19100 & 13400 & 1.0 \\
\hline
\end{tabular}

In addition, the following conditions were used.

Gas emissivity depends on fuel type. The gas emissivity in methanol is given by the following equation because the emission from the particles in ash can be ignored.

$\varepsilon_{s}=\varepsilon_{c d}+\varepsilon_{w v}$

where $\varepsilon_{c d}$ is the emissivity of carbon dioxide and $\varepsilon_{w v}$ is that of water vapor, and these are calculated from the following equations provided by Schack [12],

$$
\left\{\begin{array}{l}
\varepsilon_{c d}=0.7\left(P_{c d} L_{s}\right)^{0.5} /\left(\frac{T_{s}}{100}\right)^{0.5} \\
\varepsilon_{w v}=7.0\left(P_{w v} L_{s}\right)^{0.8} /\left(\frac{T_{s}}{100}\right)
\end{array}\right.
$$

where $P_{c d}$ is the differential pressure of carbon dioxide, $P_{w v}$ is that of water vapor and $L_{s}$ is the average optical length for smoke layer.

As for the generation rates of carbon dioxide and water vapor, the combustion of methanol is assumed to be complete. The generation rates of carbon dioxide, $\dot{\Gamma}_{c d}$, and water vapor, $\dot{\Gamma}_{w v}$, can be expressed as follows [13] because the chemical equation is $2 \mathrm{CH}_{4} \mathrm{O}+3 \mathrm{O}_{2} \rightarrow 2 \mathrm{CO}_{2}+4 \mathrm{H}_{2} \mathrm{O}$.

$$
\left\{\begin{array}{l}
\dot{\Gamma}_{c d}=s_{o x} \dot{m}_{b} \times \frac{44}{32} \times \frac{2}{3} \\
\dot{\Gamma}_{w v}=s_{o x} \dot{m}_{b} \times \frac{18}{32} \times \frac{4}{3}
\end{array}\right.
$$

Finally, the flame height and fire plume change depending on the fuel position relative to the wall. The influence becomes small if the distance between fire source and wall is at least twice the fire source diameter [14]. Hence it was assumed that the fuel position is in a corner of walls because the distances from two walls are less than twice the diameter of fire source.

\section{Comparison and Discussion for the Results of Calculations (CAL) and Experiments (EXP)}

\section{Effectiveness of the Combustion Model about Mass Loss Rate}

Figure 5 shows some results of the calculations and experiments on mass loos rate. Fig. 5a and Fig. 5b represent fuel-controlled and ventilation-controlled fires respectively. The experiments shown in the figure are the moving average of the before and after 30 data points in each time. A satisfactory prediction for the time series variation of mass loss rate was obtained for each fire case. In Fig. 5a, the mass loss rate did not 
decrease in the heat transfer rate from flame, but increased by the thermal feedback from surroundings based on Eq. 12. As a result, the values were larger than that in the open air. On the other hand, in Fig. 5b, which case was the smallest opening size and the largest fuel surface area, the reduction effect of the flame heat transfer was obvious. The fuel burning model involves the effect that the flame heat transfer decreases according to the lack of the required amount of oxygen for combustion. In this case, hence the mass loss rate decreased much smaller than that in the open air.

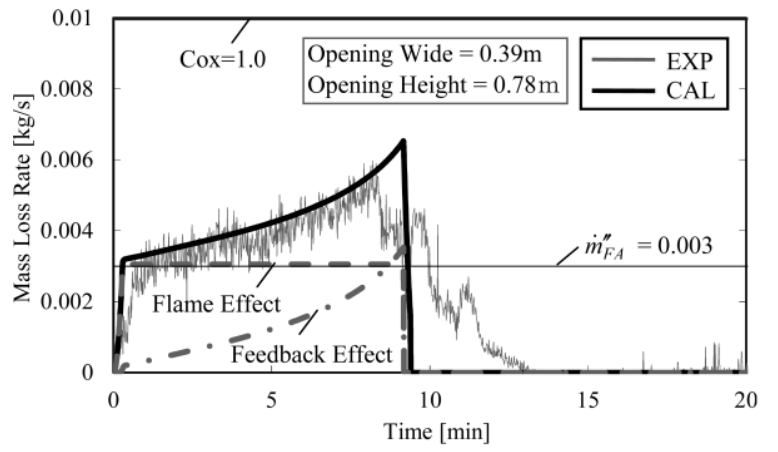

(a)

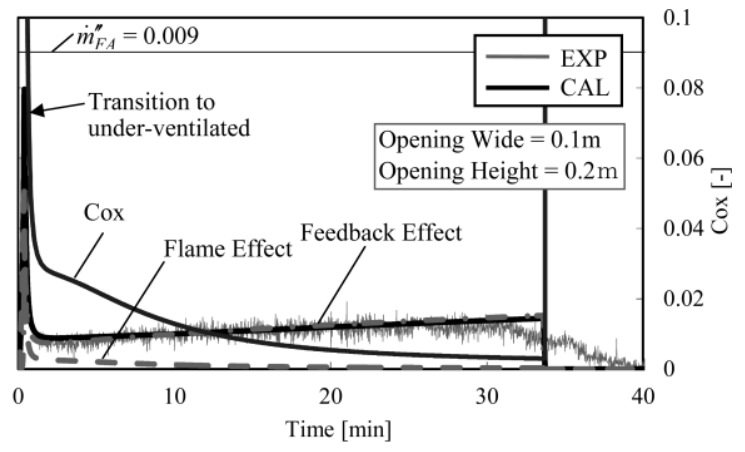

(b)

Fig. 5. Effect of burning model about mass loss rate: (a) A2-W0.39H0.78; (b) A4-W0.1H0.2.

\section{Comparison of Typical Values}

Figure 6 shows comparisons of the typical values of the experiments and calculations. Both of them in the figure are the mean values of 10 data points at just before the decay about each parameter. The outline symbols refer to the case where no visible flame was ejected from the opening in the experiments, and the solid colored symbols refer to the case where visible flame was ejected. The errors of predictions about mass loss rate became as large as $35.2 \%$ in one case, but the values in almost cases were plotted in the vicinity of the straight line in the figure. The errors of predictions for compartment temperature were not as identical as those for the mass loss rate and the calculations tend to be lower than experiments in the cases of Type A1 and A2 with flame ejected. But its error was $27.1 \%$ at maximum and $13.2 \%$ on average, which can be considered as a satisfactory prediction result.

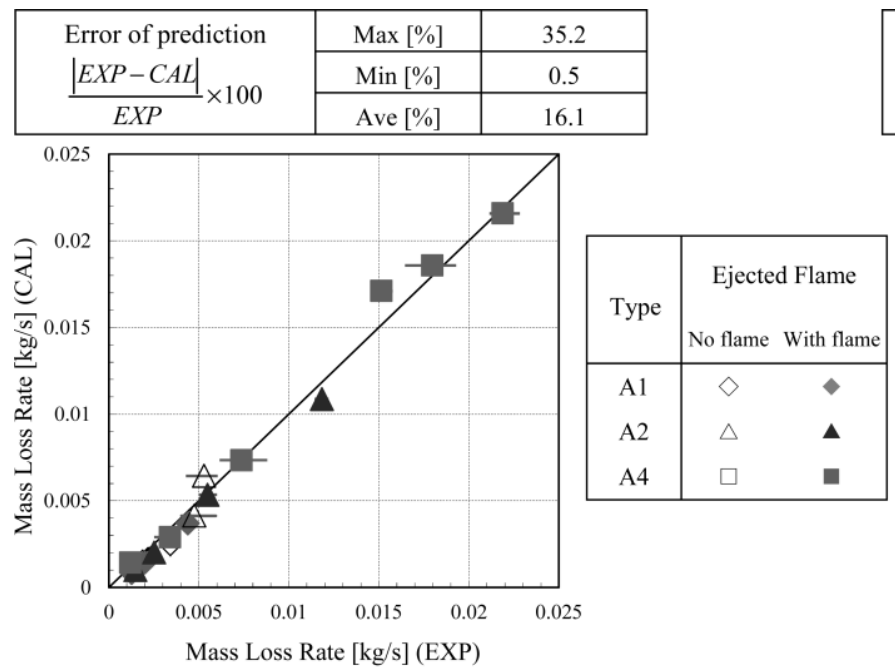

(a) Mass Loss Rate

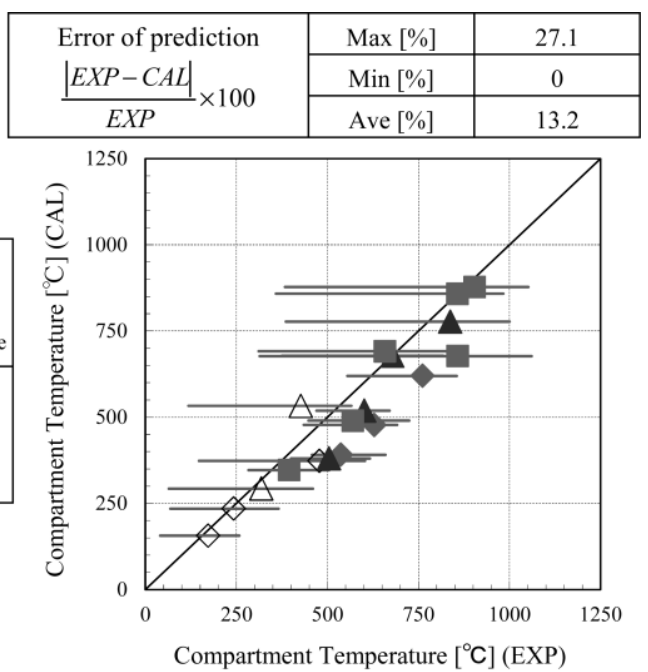

(b) Compartment Temperature

Fig. 6. Comparison between calculated and experimented results; the bars indicate the difference between maximum and minimum values: (a) mass loss rate; (b) compartment temperature. 


\section{Combustion Governing Factor and Mass Loss Rate}

The mass loss rate per unit area, $\dot{m}_{F} / A_{F}$, versus the combustion governing factor, $x=A \sqrt{H} / A_{F}$, is presented in Fig. 7. The solid line in the figure represents the boundary equation for flame ejected, $\dot{m}_{F}=0.077 A \sqrt{H}$, dividing the theoretical air inflow rate $0.5 A \sqrt{H}$ under a fully-developed fire by the stoichiometric air-to-fuel mass ratio [13], in addition to the mass loss rate equation $\dot{m}_{F}=0.1 A \sqrt{H}$ proposed by Sekine and Kawagoe. As indicated by the experiments, when the combustion governing factor becomes small, the mass loss rate usually follows $\dot{m}_{F}=0.1 A \sqrt{H}$. On the other hand, when the combustion governing factor becomes large, this relation broke down and the mass loss rate generally closed to the value in the open air. In the same way, the calculations also showed this tendency.

The area marked with the dashed line in Fig. 7 indicates the cases with flame ejected, which was confirmed by visual observation and obtained the positive value from Eq. 19. These cases were agreement between the experiments and the calculations for all cases.

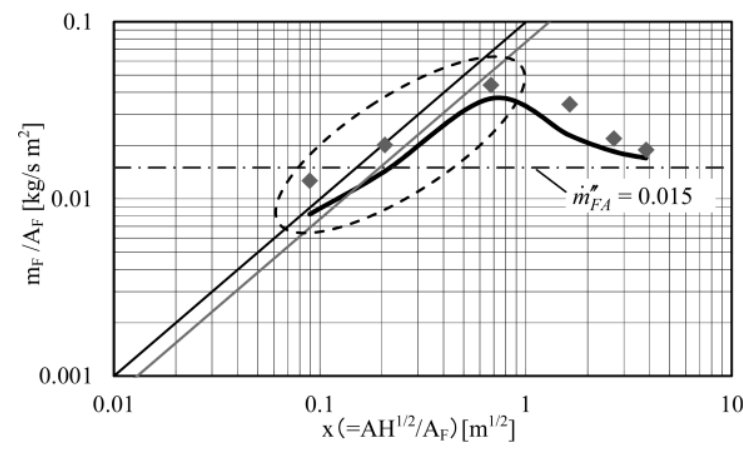

(a)

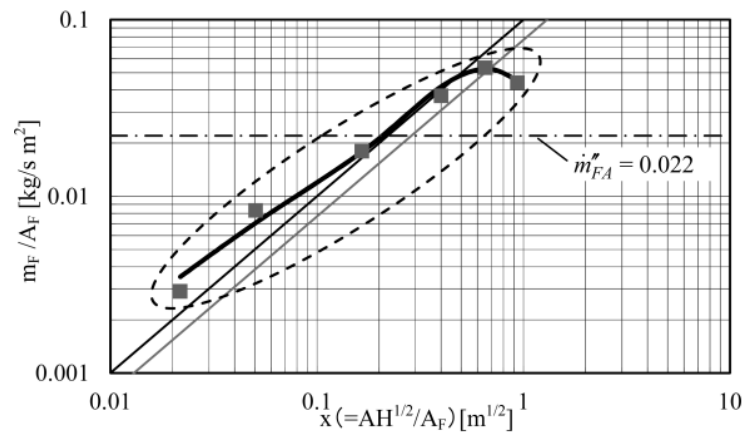

(c)

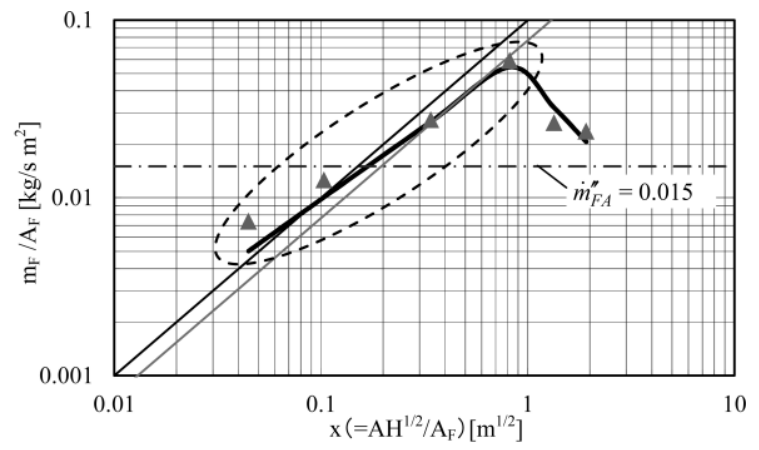

(b)

\begin{tabular}{|c|c|c|}
\hline Type & EXP & \multirow{2}{*}{ CAL } \\
\hline $\mathrm{A} 1$ & $\bullet$ & \\
\hline $\mathrm{A} 2$ & $\boldsymbol{\Delta}$ & \\
\hline $\mathrm{A} 4$ & $\mathbf{0}$ & \\
\hline
\end{tabular}

$$
\begin{array}{ll}
-\cdots & \text { Ejected Flame } \\
-\cdots & \text { Mass Loss Rate in the Open Air } \\
& \dot{m}_{F}=0.1 \mathrm{~A} \sqrt{H} \\
& \dot{m}_{F}=0.077 \mathrm{~A} \sqrt{H}
\end{array}
$$

Fig. 7. Mass loss rate versus ventilation parameter for fuel type: (a) A1; (b) A2; (c) A4.

\section{CONCLUSIONS}

This paper integrates a compartment fire zone model with the prediction of the transient fuel mass loss rate as the fire develops from fuel-controlled to ventilation-controlled conditions. The prediction of mass loss rate is influenced by: (i) the flame heat transfer as modified in reduced oxygen concentrations, and (ii) the thermal feedback from surroundings. The compartment zone model changes from two-zone to one-zone as the conditions change from fuel-controlled to ventilation-controlled inside the compartment. Predictions of the model are compared and validated with experiments providing the following results:

(1) The consideration of the rate of flame heat transfer and the thermal feedback from surroundings makes it possible to predict the transient mass loss rate.

(2) The reduction rate of the flame heat transfer can be obtained by using the stoichiometric ratio between oxygen and gasification fuel based on the zone concept (see Eq. 3). 
(3) The clear distinction between the mass loss rate and the mass burning rate also makes it possible to predict the generation of ejected flame from opening.

\section{REFERENCES}

[1] Stern-Gottfried, J., Rein, G., Bisby, L., and Torero, J., (2010) Experimental review of the homogeneous temperature assumption in post-flashover compartment fires, Fire Safety Journal 45(4): 249-261. http://dx.doi.org/10.1016/j.firesaf.2010.03.007

[2] Kawagoe, K., and Sekine, T., (1963) Estimation of fire temperature rise curves in concrete buildings (Part 1), Transactions of the Architectural Institute of Japan 85: 38-43.

[3] Tanaka, T. and Yamada, S., (2004) Bri2002: Two Layer Zone Smoke Transport Model -chapter 1 Outline of the Mode-, Fire Science and Technology 23(1): 1-44. http://dx.doi.org/10.3210/fst.23.1

[4] Tewarson, A., (1981) The influence of oxygen concentration on fuel parameters for fire modeling, Symposium (International) on Combustion 18(1): 563-570. http://dx.doi.org/10.1016/S0082$\underline{0784(81) 80061-6}$

[5] Thomas, I. and Bennetts, I., (2000) Fires in Enclosures with Single Ventilation Openings Comparison of Long and Wide Enclosures, Fire Safety Science 6: 941-952. http://dx.doi.org/10.3801/IAFSS.FSS.6-941

[6] Utiskul Y., "Theoretical and experimental study on fully developed compartment fires", NIST GCR 07-907, 2007.

[7] Tanaka, T., (1980) A study on modeling of fire in small scale building (3), Bulletin of Japanese Association of Fire Science and Engineering 30(1): 7-18.

[8] Drysdale, D., An Introduction to Fire Dynamics (2nd ed.), Wiley, Chichester, 1998.

[9] Cadorin J. and Franssen J-M., (2003) A tool to design steel elements submitted to compartment fires-OZone V2. Part 1: pre- and post-flashover compartment fire model, Fire Safety Journal 38(5): 395-427. http://dx.doi.org/10.1016/S0379-7112(03)00014-6

[10] Tewarson, A., "Generation of Heat and Gaseous, Liquid, Nitrogen, and Sulfur Atoms," The SFPE Handbook of Fire Protection Engineering ( $4^{\text {th }} e d$.), National Fire Protection Association, Quincy, MA, 2008, p. 3/109-3/194.

[11] Babrauskas, V., "Heat Release Rates," The SFPE Handbook of Fire Protection Engineering ( $^{\text {th }}$ ed.), National Fire Protection Association, Quincy, MA, 2008, p. 3/1-3/59.

[12] JSME Date Book, Heat Transfer ( $3^{\text {rd }}$ ed.), Japan Society of Mechanical Engineers, 1975.

[13] Ohmiya, Y., Tanaka, T., and Wakamatsu, T., (1998) A Room Fire Model for Predicting Fire Spread by External Flames, Fire Science and Technology 18(1): 11-21. http://dx.doi.org/10.3210/fst.18.11

[14] Takahashi, W., Sugawa, O., Tanaka, H., and Ohtake, M., (1997) Flame and Plume Behavior in and Near a Corner of Walls, Fire Safety Science 5: 261-271. http://dx.doi.org/10.3801/IAFSS.FSS.5-261 